\title{
Ovarian Hormones and Transdermal Nicotine Administration Independently and Synergistically Suppress Tobacco Withdrawal Symptoms and Smoking Reinstatement in the Human Laboratory
}

\author{
Raina D Pang*,', Madalyn M Liautaud', Matthew G Kirkpatrick', Jimi Huh', John Monterosso² and \\ Adam M Leventhal ${ }^{1,2}$ \\ 'Department of Preventive Medicine, University of Southern California Los Angeles, CA, USA; '2Department of Psychology, University of Southern \\ California Los Angeles, CA, USA
}

\begin{abstract}
Modeling intra-individual fluctuations in estradiol and progesterone may provide unique insight into the effects of ovarian hormones on the etiology and treatment of nicotine dependence. This randomized placebo-controlled laboratory study tested the independent and interactive effects of intra-individual ovarian hormone variation and nicotine on suppression of tobacco withdrawal symptoms and smoking behavior. Female smokers randomized to $21 \mathrm{mg}$ nicotine (TNP; $n=37$ ) or placebo (PBO; $n=43$ ) transdermal patch following overnight abstinence completed three sessions occurring during hormonally distinct menstrual cycle phases. At each session, participants provided saliva for hormone assays and completed repeated self-report measures (ie, tobacco withdrawal symptoms, smoking urge, and negative affect (NA)) followed by an analog smoking reinstatement task for which participants could earn money to delay smoking and subsequently purchase cigarettes to smoke. Higher (vs lower) progesterone levels were associated with greater reductions in NA. Higher (vs lower) progesterone levels and progesterone to estradiol ratios were associated with reducing smoking urges over time to a greater extent with TNP compared to PBO. There was an interaction between Patch and estradiol on NA. With TNP, higher-than-usual estradiol was associated with greater decreases in NA. However with PBO, lower-than-usual estradiol was associated with greater decreases in NA. These results suggest that the effects of TNP on mood- and smoking-related outcomes may vary depending on the ovarian hormone levels.
\end{abstract}

Neuropsychopharmacology (2018) 43, 828-837; doi:I0.1038/npp.2017.216; published online II October 2017

\section{INTRODUCTION}

There is some evidence that females compared to males may be less successful when making a smoking quit attempt (Japuntich et al, 2011; McKee et al, 2015; Smith et al, 2015; $\mathrm{Wu}$ et al, 2015). Female smokers may have stronger motivation to reinstate smoking after abstinence than males because they experience more severe negative affect (NA), urge to smoke, and other tobacco withdrawal symptoms during abstinence (Leventhal et al, 2007; Pang and Leventhal, 2013). Additionally, female ( $v s$ male) smokers may hold stronger cognitive expectations that smoking suppresses NA (Pang et al, 2015). Consequently, there has been interest in identifying female-specific biological determinants of

* Correspondence: Dr RD Pang, Department of Preventive Medicine, University of Southern California Keck School of Medicine, 200I N. Soto Street, Room 318C, Los Angeles, CA 90032, USA, Tel: + I 323 442 725 I, Fax: + I 323442 2359, E-mail: rpang@usc.edu

Received 24 May 2017; revised 8 September 2017; accepted 10 September 2017; accepted article preview online 14 September 2017 tobacco withdrawal and smoking reinstatement during acute abstinence.

Progesterone and estradiol (the primary estrogen) - sex hormones produced by the ovaries-modulate neural systems involved in mood and reward (Engman et al, 2016; Henningsson et al, 2015; Lynch et al, 2002; Lynch and Sofuoglu, 2010) and are plausible female-specific determinants of smoking motivation (Wetherill et al, 2016). Given that these hormones fluctuate in a somewhat cyclical fashion during the menstrual cycle, initial smoking research on this topic has studied the effects of menstrual cycle phase as a proxy for endogenous estradiol and progesterone levels, but have produced inconsistent effects on tobacco withdrawal and smoking reinstatement across investigations (see Weinberger et al, 2015 for meta-analysis and review).

Staged menstrual cycle phase-based research hinges on prototypical patterns of variation in which estradiol peaks in the follicular phase (menses to ovulation) and progesterone peaks in the luteal phase (ovulation until next menses). Yet, within-phase hormone peaks are short-lived and therefore difficult to capture (eg, 3-day estradiol peak in follicular 
phase). In addition, cycle length and the magnitude and shape of within-phase ovarian hormone vary widely among females (Fehring et al, 2006; Mumford et al, 2012). Recent recommendations for smoking research calls for the direct measurement of ovarian hormones (Wetherill et al, 2016).

In one such study, larger within-person decreases in estradiol and progesterone between two experimental sessions was associated with increased puff intensity during ad lib smoking and lower progesterone to estradiol $(\mathrm{P} / \mathrm{E})$ ratios were associated with taking more puffs (Schiller et al, 2012). Further evidence comes from a 4 -week cessation trial, which found that increasing progesterone levels and $\mathrm{P} / \mathrm{E}$ were predictive of abstinence in the following week in participants receiving transdermal nicotine patch (TNP; Saladin et al, 2015). While such findings provide suggestive evidence that intra-individual variation in hormone levels and ratio of hormone levels (irrespective of cycle phase) may be important, interpreting hormone-smoking associations using standard analytic methodologies is complicated by phenotypic heterogeneity in ovarian functioning across females, such that some females have higher circulating estradiol and progesterone levels than others regardless of menstrual cycle phase (Mumford et al, 2012). Betweenperson phenotypic variation may obscure and confound the effects of intra-individual (ie, within-person) hormonal spikes or troughs across the menstrual cycle. Optimal characterization of menstrual-related hormone effects on tobacco withdrawal and reinstatement requires both: (1) repeated measurement of ovarian hormones and tobacco withdrawal and smoking reinstatement responses across multiple time points within the menstrual cycle; and (2) statistical modeling strategies capable of parsing within- and between-person variance in hormone levels (Hedeker et al, 2012).

This human laboratory study tested the independent and interactive effects of intra-individual ovarian hormone variation and TNP or placebo patch (PBO) on tobacco withdrawal symptoms, urge to smoke, NA, and an analog smoking reinstatement task at three visits spanning different points of the menstrual cycle. Multi-level repeated measures statistical modeling strategies were used to parse within- and between-person variance to isolate the direct effects of intraindividual changes in ovarian hormone levels and whether these effects were different across TNP and PBO. Given suggestive prior evidence of inverse associations of progesterone with smoking urge and behavior (Schiller et al, 2012; Sofuoglu et al, 2011), we hypothesized when women were tested at higher than the person-level average levels of progesterone, they would exhibit lower smoking urges, lapse behavior, and cigarettes smoked. Additionally, given evidence that the effects of progesterone on smoking outcomes may depend on nicotine, we hypothesized that the effects of progesterone would be greater in the TNP compared to the PBO condition. Findings have not shown as strong of a role for estradiol on smoking-related outcomes. However, one study did find decreasing estradiol levels increased smoking (Schiller et al, 2012). Thus, we hypothesized that participants would smoke fewer cigarettes when estradiol is higher-thanusual. Lastly, we hypothesized that participants would smoke less when $\mathrm{P} / \mathrm{E}$ ratios are higher.

\section{MATERIALS AND METHODS}

\section{Participants}

Participants were 124 female, non-treatment-seeking daily smokers recruited from the Los Angeles area via advertisements for a paid study on the menstrual cycle and smoking. The University of Southern California Internal Review Board approved all procedures, and all participants provided informed consent. Inclusion criteria required participants to (a) be 18-40 years of age, (b) report regular menstrual cycles lasting 24-35 days in the past 3 months, (c) be a regular smoker for at least the past year ( $\geqslant 10$ cigarettes/day), (d) have normal eyesight, and (e) be fluent in English. Exclusion criteria included (a) current non-nicotine substance dependence, (b) baseline breath carbon monoxide (CO) levels of $<10 \mathrm{ppm}$, (c) current use of nicotine replacement therapy, psychiatric medications implicated in smoking cessation, or regular use of any other tobacco products, (d) past 3-month use of hormonal medications including birth control, (e) history of hysterectomy or intent to obtain hysterectomy in the next 30 days, (f) a desire to quit or to substantially reduce smoking in the next 30 days, (g) pregnancy or breastfeeding in the past 6 months or intent to get pregnant in the next 30 days, (h) history of medical contraindications for nicotine patch (eg, arrhythmia, hypertension), and (i) allergy to capsaicin cream.

Following a preliminary telephone eligibility screening, potentially eligible participants $(n=174)$ were scheduled for an in-person screening session. Of those screened, 124 were deemed eligible at baseline. Of these, 26 participants did not complete any experimental sessions including one that was dropped for twice failing to meet abstinence criteria during the first experimental session, 16 (TNP $n=9$, PBO $n=7$ ) completed only one experimental session including one that was excluded for a positive pregnancy test prior to the second experimental session, and 1 in the TNP condition completed only two experimental sessions. Additionally, one participant was removed from analyses because they did not have usable hormonal data from all three experimental sessions (ie, estradiol data from one experimental session was found to be over $10 S D$ above the sample's mean estradiol level). This left a sample of 80 participants with data from all three experimental sessions included in the final analyses.

\section{Design and Procedure}

Participants attended an in-person screening session involving informed consent, eligibility assessments, and completion of baseline measures. Participants subsequently attended three identical in-person experimental sessions that corresponded with days of the menstrual cycle associated with distinct hormone level profiles: early follicular (EF), late follicular (LF), and mid-luteal (ML) corresponding to roughly days $1-5,11-13$, and $17-20$ for a 28 -day cycle.

Experimental sessions began at 8:30 am and ended at 5:00 pm. Sessions began with the administration of a pregnancy test and breath CO (Vitalograph Inc, Lenexa, KS) and alcohol breathalyzer analyses (BACtrack Select S80; BACtrack Breathalyzers/KHN Solutions, Inc., San Francisco, CA). Individuals showing non-compliance with smoking abstinence (ie, $\mathrm{CO}>9 \mathrm{ppm})$ were rescheduled $(n=10)$ and those 
found non-compliant twice were dropped from further participation $(n=1)$. Patch administration occurred approximately $30 \mathrm{~min}$ after the start of the experimental session and patch removal occurred approximately 295 min after administration. All patches were concealed with a gauze bandage treated with capsaicin $0.075 \%$ cream, which provides a minor tingling sensation to prevent the detection of any skin irritation caused by active TNP (NicoDerm CQ; GlaxoSmithKline, Research Triangle Park, NC; Gilbert et al, 2005). For the remainder of the experimental session, participants completed (a) subjective and cardiovascular assessments administered $10 \mathrm{~min}$ prior to patch administration, and then at $10,40,70,100,130,160,225,280,430$, and $460 \mathrm{~min}$ after patch administration; (b) cognitive tasks assessing attentional processes and response inhibition (data not reported here); and (c) an analog smoking reinstatement task assessing acute motivation to reinstate smoking that began $300 \mathrm{~min}$ after patch administration (5 min after patch removal).

\section{Measures}

Ovarian hormones. Participants provided $2 \mathrm{ml}$ saliva samples for progesterone and estradiol hormone assays at the outset of all sessions. Samples were stored on site in a 203.15 K freezer before being shipped overnight on dry ice to Salimetrics, LLC (Carlsbad, CA) for salivary estradiol and progesterone enzyme immunoassays. Salivary estradiol and progesterone have been shown to correlate with levels measured by serum and plasma and to reliably detect hormone peaks during normal ovulatory cycles (Choe et al, 1983; Riad-Fahmy et al, 1983; Shirtcliff et al, 2000; Worthman et al, 1990).

The Minnesota nicotine withdrawal scale. The Minnesota nicotine withdrawal scale (MNWS; Hughes and Hatsukami, 1986): This study used an eight-item variant of the MNWS (ie, craving for nicotine, irritable/angry, anxious/tense, difficulty concentrating, restlessness, impatient, excessive hunger, and increased eating), which is a widely used measure of tobacco withdrawal. Participants rated the severity of symptoms experienced 'right now' on a 6-point Likert scale from 0 (none) to 5 (severe). A mean score was calculated from all items with higher scores indicating greater withdrawal severity (Leventhal et al, 2010). Previous studies demonstrate that the MNWS exhibits satisfactory internal consistency and construct validity (Toll et al, 2007).

The brief questionnaire of smoking urges. The brief questionnaire of smoking urges (QSU; Cox et al, 2001): The QSU is a 10-item scale assessing smoking urges experienced 'right now.' Items are self-statements of urge states (eg, 'I have a desire for a cigarette now'). Participants rated their agreement with each item using a 6-point Likert scale from 0 (strongly disagree) to 5 (strongly agree). A mean score of all items was calculated, with higher scores indicating greater smoking urge. The QSU has demonstrated excellent psychometric properties in previous samples (Cox et al, 2001).
The positive and negative affect schedule. The positive and negative affect schedule (PANAS; Watson et al, 1988): This study utilized the 10-item NA (eg, 'irritable,' 'afraid,' 'distressed') subscale. Participants rated the extent to which they experienced NA items 'right now' on 5-point Likert scale from 1 (very slightly) to 5 (extremely), with higher scores indicating greater overall NA experienced. The PANAS has shown excellent psychometric properties (Watson et al, 1988).

Analog smoking reinstatement task. The analogue smoking reinstatement task (McKee, 2009) measures ability to resist smoking reinstatement under conditions in which it is advantageous to remain abstinent (McKee, 2009; McKee et al, 2006). Responses on this task have been shown to be sensitive to tobacco abstinence (Leeman et al, 2010). During this task, participants are monetarily rewarded to (a) delay the opportunity to smoke (outcome: length delayed to first cigarette (range: 0-50 min)), and (b) smoke fewer cigarettes once given the opportunity to smoke (outcome: number of cigarettes smoked (range: 0-8)). See Pang and Leventhal (2013) for full task protocol.

Demographic, menstrual assessment, and smoking history questionnaire. An author-constructed questionnaire was used to obtain demographic information, menstrual cycle regularity (eg, dates of last two menstrual cycles, average cycle length), and smoking characteristics (eg, cigarettes smoked per day).

Fagerström test for nicotine dependence. The Fagerström test for nicotine dependence (FTND) (Heatherton et al, 1991 ) is a six-item self-report measure of nicotine dependence severity. Scores range from 0 to 10 , with higher scores reflecting greater nicotine dependence. The FTND has shown good predictive and convergent validity to both dependence-related biochemical markers and self-report measures (Payne et al, 1994).

\section{Data Analysis}

Preliminary analyses. Preliminary analyses involved comparing sample characteristics in the full sample and by Patch (TNP vs PBO). T-tests and chi-square tests were used to evaluate whether patch-type group differed in continuous and categorical/ordinal demographic and smoking characteristics, respectively. Generalized estimating equations were run between sample characteristics and outcomes, and those that significantly associated with outcomes were included as covariates in primary models. Preliminary analyses also involved plotting the distribution of raw hormonal data in histograms (Supplementary Figure 1). General linear mixed models were conducted to test whether: (1) estradiol and progesterone levels differed between phases (EF was used as the reference phase because it is considered the hormonal baseline), and (2) within-subject estradiol levels associated with within-subject progesterone levels. As a manipulation check, general linear mixed models were conducted to test main effects of Patch on smoking- and withdrawal-related outcomes and Patch $\times$ time interactions on withdrawalrelated outcomes. To determine whether phase independently 
associated with outcomes, general linear mixed models were conducted to test the main effect of phase (reference phase $=\mathrm{EF}$; controlling for patch, time, and all covariates included in the final models) on smoking- and withdrawalrelated outcomes.

Primary analyses. To determine within-person changes in ovarian hormones, estradiol and progesterone levels were person-centered (ie, [Session hormone level]-[Person's average hormone level across all sessions]; Enders and Tofighi, 2007). Thus, the within-subject estradiol and progesterone levels reflect session deviation from one's own personal mean for each hormone, with positive values reflecting higher-than-usual levels and negative values reflecting lower-than-usual levels for that individual. Additionally, to control for phenotypic variance in propensity towards high or low hormones, between-subject (ie, grand mean centered) estradiol and progesterone variables were computed and added as covariates. Phase was included as a planned categorical variable in order to examine the predictive validity of hormone levels on outcomes beyond that of menstrual cycle phase.

General linear mixed models were conducted to test main and interactive effects of Patch and within-subject changes in estradiol and progesterone on smoking- and withdrawalrelated outcomes. Withdrawal outcomes (ie, MNWS, QSU, PANAS-NA) were assessed over time (ie, every $30 \mathrm{~min}$ with the first measurement occurring approximately $10 \mathrm{~min}$ after patch administration) and were modeled as change from baseline (ie, [assessment score] - [pre-patch score]). For the withdrawal-related outcomes: Model 1 included Patch, time (ie, repeated assessments occurring at each session), the interaction of Patch $\times$ time, within and between-subject effects of progesterone, and covariates; Model 2 added Patch $\times$ within-subject progesterone, and time $\times$ within-subject progesterone; and Model 3 added the three-way interaction of Patch $\times$ within-subject progesterone $\times$ time. As analog smoking reinstatement task outcomes were only measured once per experimental session, a time factor was not needed for these outcomes. For analog smoking reinstatement task outcomes: Model 1 included Patch, within- and between-subject effects of progesterone, and covariates; Model 2 added the interaction of within-subject progesterone $\times$ Patch. Identical models were conducted with estradiol and $\mathrm{P} / \mathrm{E}$ as the hormone predictor. To control for overall error rate due to multiple testing (ie, 3 hormones $\times 5$ outcomes $=15$ tests), we used a Bonferroni corrected $p<0.003$. All statistical analyses were conducted in SPSS, version 22 .

\section{RESULTS}

\section{Preliminary Analyses}

As depicted in Table 1, there were no significant differences between patch groups on any demographics or smoking characteristics. Race (African American/Black vs other), years of regular smoking, number of cigarettes a day, FTND, and number of past serious quit attempts associated with at least one outcome and were included as covariates along with the planned covariates of phase and between subject hormone levels in all models. Estradiol was significantly lower in the EF than LF phase (estimate $=0.38, p=0.02$ ). Progesterone was significantly lower in the EF than ML phase (estimate $=0.08, p<0.001$ ). Within-subject estradiol was significantly associated with within-subject progesterone (estimate $=3.14, p<0.001$ ). Menstrual cycle phase did not significantly associate with time to start smoking, MNWS, QSU, or NA (estimates $=-0.95$ to.05, $p$ s $>0.07$ ). Participants smoked less cigarettes during the LF than EF menstrual cycle phase (estimate $=-0.24, p=0.03$ ).

MNWS and QSU decreased from pre-patch administration to a greater extent over time with TNP compared to PBO (Patch $\times$ time interactions: estimates $=-0.04$ to -0.10 , $p s<0.05$; Figure $1 \mathrm{a}$ and $\mathrm{b})$. Participants receiving TNP compared to $\mathrm{PBO}$ waited longer to smoke (Main effect of Patch: estimate $=14.45, p=0.001)$ and smoked fewer cigarettes (Main effect of Patch: estimate $=-0.44, p=0.03$ ).

\section{Primary Analyses}

Within-person progesterone effects. There was a main effect of within-subject progesterone, such that higher within-subject progesterone level was associated with larger change in baseline decreases in NA (Table 2, Model 1: estimate $=-0.63, p<0.001)$. Additionally, the within-person effect of progesterone on decreases from pre- to post-patch was even greater with TNP compared to PBO for QSU (Table 2, Model 3: estimate $=-1.35, p<0.001$; Figure 1c). There were no significant main or interactive effects of within-subject progesterone on MNWS or the analog smoking reinstatement task (Table 2).

Within-subject estradiol effects. There was a main effect of within-subject estradiol, such that higher within-subject estradiol level was associated with a larger decrease from baseline in NA (Table 3, Model 1: estimate $=-0.05$, $p=0.002)$. Higher-than-usual estradiol was associated with a diverging pattern across $\mathrm{PBO}$ and TNP with greater decreases in NA with TNP, but smaller decreases with PBO (Table 3, Model 2: estimate $=-0.12, p<0.001$; Figure 1d). There were no significant main or interactive effects of within-subject estradiol on MNWS, QSU, or the analog smoking reinstatement task.

Within-subject $P / E$ ratio effects. Higher within-subject $\mathrm{P} / \mathrm{E}$ ratios were associated with lower QSU change from baseline (Table 4, Model 1: estimate $=-3.18, p=0.002$ ). There was also a significant patch $\times \mathrm{P} / \mathrm{E}$ ratios $\times$ time interaction showing that the effect of the ratio on QSU was greater with TNP compared to $\mathrm{PBO}$ (Table 4, Model 3: estimate $=-3.38$, $p<0.001)$. There were no significant main or interactive effects of $\mathrm{P} / \mathrm{E}$ ratios on $\mathrm{MNWS}, \mathrm{NA}$, or the analog smoking reinstatement task.

\section{DISCUSSION}

In this study, we found that higher-than-usual progesterone was associated with greater decreases in NA from baseline among acutely abstinent premenopausal female smokers. These findings are consistent with prior studies that have found that during high compared to low progesterone phase of the menstrual cycle, women are better at managing their 
Ovarian hormones and transdermal nicotine administration

RD Pang et al

Table I Sample Demographic and Smoking Characteristics

\begin{tabular}{|c|c|c|c|c|c|}
\hline & $\begin{array}{l}\text { Full sample } \\
\qquad(n=80)^{\mathrm{a}}\end{array}$ & $\begin{array}{l}\text { Placebo } \\
(n=43)^{b}\end{array}$ & $\begin{array}{l}\text { Nicotine } \\
(n=37)^{c}\end{array}$ & & \\
\hline & $\begin{array}{c}M(S D) \text { or } n \\
(\%)\end{array}$ & $\begin{array}{c}M(S D) \text { or } n \\
(\%)\end{array}$ & $\begin{array}{c}M(S D) \text { or } n \\
(\%)\end{array}$ & t or $\chi^{2}$ & $p$ \\
\hline \multicolumn{6}{|l|}{ Demographics } \\
\hline Age (years) & $29.89(5.99)$ & $29.42(6.10)$ & $30.43(5.9 \mid)$ & -0.75 & 0.45 \\
\hline Race & & & & 2.29 & 0.13 \\
\hline $\begin{array}{l}\% \text { African } \\
\text { American/Black }\end{array}$ & $36(45.0 \%)$ & $16(37.2 \%)$ & $20(54.1 \%)$ & & \\
\hline Education & & & & 2.60 & 0.27 \\
\hline $\begin{array}{l}\text { High school or } \\
\text { less }\end{array}$ & $26(32.5 \%)$ & 12 (27.9\%) & $14(37.8 \%)$ & & \\
\hline Some college & $38(47.5 \%)$ & 24 (55.8\%) & $14(37.8 \%)$ & & \\
\hline $\begin{array}{l}\text { College or } \\
\text { beyond }\end{array}$ & $16(20.0 \%)$ & 7 (16.3\%) & 9 (24.3\%) & & \\
\hline $\begin{array}{l}\text { Average cycle } \\
\text { length (days) }\end{array}$ & $29.38(1.84)$ & $29.35(1.91)$ & $29.42(1.78)$ & -0.18 & 0.86 \\
\hline \multicolumn{6}{|l|}{$\begin{array}{l}\text { Smoking } \\
\text { characteristics }\end{array}$} \\
\hline FTND & $4.95(1.95)$ & $4.60(2.01)$ & $5.35(1.83)$ & -1.74 & 0.09 \\
\hline $\begin{array}{l}\text { Screening } \\
\text { session CO }\end{array}$ & I7.33 (6.61) & I7.37 (5.98) & I 7.27 (7.35) & 0.07 & 0.95 \\
\hline Cigarettes/day & | $3.90(4.97)$ & I $3.16(4.25)$ & | $4.76(5.63)$ & -1.44 & 0.15 \\
\hline $\begin{array}{l}\text { Years regular } \\
\text { smoker }\end{array}$ & | $1.06(6.43)$ & | $0.23(6.52)$ & $12.03(6.26)$ & -1.25 & 0.22 \\
\hline $\begin{array}{l}\text { Number of } \\
\text { serious quit } \\
\text { attempts }\end{array}$ & $3.85(11.36)$ & $3.35(4.59)$ & $4.43(16.07)$ & -0.42 & 0.67 \\
\hline \multicolumn{6}{|l|}{$\begin{array}{l}\text { MCD experimental } \\
\text { session }\end{array}$} \\
\hline $\mathrm{EF}$ & $3.29(1.43)$ & $3.26(1.36)$ & $3.32(1.53)$ & -0.19 & 0.85 \\
\hline LF & $12.46(2.63)$ & I $2.65(2.84)$ & I2.22 (2.38) & 0.72 & 0.47 \\
\hline$M L$ & $20.92(2.6 I)$ & $20.58(2.84)$ & $21.35(2.25)$ & -1.29 & 0.20 \\
\hline \multicolumn{6}{|l|}{$\begin{array}{l}\text { Hours abstinent } \\
\text { experimental } \\
\text { session }\end{array}$} \\
\hline $\mathrm{EF}$ & I $7.89(5.37)$ & | $8.27(7.29)$ & I $7.45(0.92)$ & 0.68 & 0.51 \\
\hline LF & $17.98(4.36)$ & $18.10(4.38)$ & I $7.84(4.39)$ & 0.26 & 0.79 \\
\hline$M L$ & $17.52(3.21)$ & $|8.0|(4.22)$ & $16.96(1.13)$ & 1.57 & 0.12 \\
\hline \multicolumn{6}{|l|}{$\begin{array}{l}\text { Estrogen } \\
\text { experimental } \\
\text { sessions ( } p g / m l)\end{array}$} \\
\hline $\mathrm{EF}$ & $2.23(1.16)$ & $2.44(1.40)$ & $1.98(0.76)$ & 1.86 & 0.07 \\
\hline LF & $2.60(1.36)$ & $2.56(1.20)$ & $2.66(1.53)$ & -0.32 & 0.75 \\
\hline$M L$ & $2.59(1.36)$ & $2.86(1.50)$ & $2.27(1.11)$ & 1.98 & 0.05 \\
\hline
\end{tabular}

Progesterone

experimental

sessions ( $\mathrm{ng} / \mathrm{ml})$

Neuropsychopharmacology 
Table I Continued

\begin{tabular}{|c|c|c|c|c|c|}
\hline & $\begin{array}{l}\text { Full sample } \\
\qquad(n=80)^{\mathrm{a}}\end{array}$ & $\begin{array}{l}\text { Placebo } \\
(n=43)^{b}\end{array}$ & $\begin{array}{l}\text { Nicotine } \\
(n=37)^{c}\end{array}$ & & \\
\hline & $\begin{array}{c}M(S D) \text { or } n \\
(\%)\end{array}$ & $\begin{array}{c}M(S D) \text { or } n \\
(\%)\end{array}$ & $\begin{array}{c}M(S D) \text { or } n \\
(\%)\end{array}$ & $\operatorname{tor} \chi^{2}$ & $p$ \\
\hline $\mathrm{EF}$ & $0.13(0.09)$ & $0.14(0.11)$ & $0.11(0.06)$ & 1.74 & 0.09 \\
\hline LF & $0.14(0.09)$ & $0.16(0.08)$ & $0.13(0.09)$ & 1.42 & 0.16 \\
\hline$M L$ & $0.20(0.12)$ & $0.23(0.14)$ & $0.18(0.10)$ & 2.03 & 0.05 \\
\hline \multicolumn{6}{|c|}{$\begin{array}{l}\text { MNWS baseline } \\
\text { scores }\end{array}$} \\
\hline$E F$ & $1.79(1.24)$ & $1.95(1.24)$ & $1.61(1.24)$ & 1.24 & 0.22 \\
\hline LF & $1.49(1.20)$ & $1.47(1.05)$ & $1.52(1.37)$ & -0.21 & 0.83 \\
\hline$M L$ & $1.52(1.06)$ & $1.55(1.07)$ & $1.50(1.06)$ & 0.21 & 0.83 \\
\hline \multicolumn{6}{|c|}{$\begin{array}{l}\text { QSU baseline } \\
\text { scores }\end{array}$} \\
\hline$E F$ & $3.10(1.36)$ & $3.04(1.24)$ & $3.16(1.50)$ & -0.41 & 0.68 \\
\hline $\mathrm{LF}$ & $2.97(1.45)$ & $2.78(1.39)$ & $3.18(1.51)$ & -1.24 & 0.22 \\
\hline$M L$ & $3.00(1.33)$ & $2.89(1.38)$ & $3.13(1.27)$ & -0.80 & 0.42 \\
\hline \multicolumn{6}{|c|}{$\begin{array}{l}\text { PANAS NA } \\
\text { baseline scores }\end{array}$} \\
\hline $\mathrm{EF}$ & $1.39(0.50)$ & $1.48(0.61)$ & $1.29(0.33)$ & 1.79 & 0.08 \\
\hline LF & $1.37(0.61)$ & $1.34(0.44)$ & I.4| (0.77) & -0.46 & 0.64 \\
\hline$M L$ & $1.39(0.58)$ & $1.40(0.45)$ & $1.38(0.7 \mid)$ & 0.14 & 0.89 \\
\hline
\end{tabular}

Abbreviations: CO, carbon monoxide; EF, early follicular, FTND, Fagerström Test for Nicotine Dependence (range: 0-10); CO, carbon monoxide; LF, late follicular; MCD, menstrual cycle day; ML, mid luteal; MNWS, Minnesota Nicotine Withdrawal Scale; PANAS NA, Positive and Negative Affect Schedule Negative Affect; QSU, Brief Questionnaire of Smoking Urges.

Note: Ns ranged from ${ }^{a} 77-80,{ }^{b} 42-43$, and ${ }^{\mathrm{c}} 34-37$ due to patterns of missing data.

emotions (Milivojevic et al, 2014) and have lower NA following overnight tobacco abstinence (DeVito et al, 2014). The effects of progesterone on NA did not differ across nicotine patch type or time, which is consistent with a prior study showing that the effect of high progesterone compared to low progesterone menstrual cycle phase did not interact with time (baseline $v s$ end of session) to impact NA following intravenous nicotine administration (DeVito et al, 2014). This study also found an interactive effect such that withinperson covariation of progesterone with lower urge was greater in TNP than PBO, which is consistent with a previous study finding that after smoking a high-nicotine cigarette, cigarette craving was blunted in women with high compared to low progesterone levels in the luteal phase (Goletiani et al, 2015).

Similarly, we found that higher $\mathrm{P} / \mathrm{E}$ ratios were associated with greater decreases in smoking urge. Prior studies have found that administration of progesterone compared to placebo during the EF phase (ie, when estradiol levels are low) reduced urge to smoke in acutely abstinent smokers (Sofuoglu et al, 2001,2011). There was also an interaction with patch and time such that the within-person covariation of $\mathrm{P} / \mathrm{E}$ ratios on urge to smoke over time was greater in with TNP compared to PBO. Taken together with our findings on within-subject progesterone levels, these results highlight that higher progesterone may decrease smoking urge and this effect may be enhanced with the addition of nicotine.

We also found that intra-individual variance in estradiol was associated with lower NA. A previous study found that women with relatively high compared to relatively low estradiol levels experienced less distress following a stress task (Albert et al, 2015). Thus, it is possible that higher-thanusual estradiol may offset some affective distress occurring due to abstinence. Additionally, the effects of estradiol on NA differed with TNP (estradiol associated with larger decreases in NA) and PBO (estradiol associated with smaller decreases in NA).

We did not find intra-individual covariation of progesterone, estradiol, or $\mathrm{P} / \mathrm{E}$ ratios and smoking behavior on the analog smoking reinstatement task. Prior studies have shown that decreasing progesterone and estradiol levels associated with increased smoking (Schiller et al, 2012) and decreasing progesterone levels with greater odds of smoking during a cessation attempt (Saladin et al, 2015). Additionally, increasing $\mathrm{P} / \mathrm{E}$ ratio was associated with increased smoking abstinence (Saladin et $a l, 2015$ ) and higher $\mathrm{P} / \mathrm{E}$ ratio was associated with smoking less (ie, fewer puffs and less weight of cigarette smoked; Schiller et al, 2012). Given that these prior studies utilized treatment-seeking samples (Saladin et al, 2015; Schiller et al, 2012), it is possible the role of 


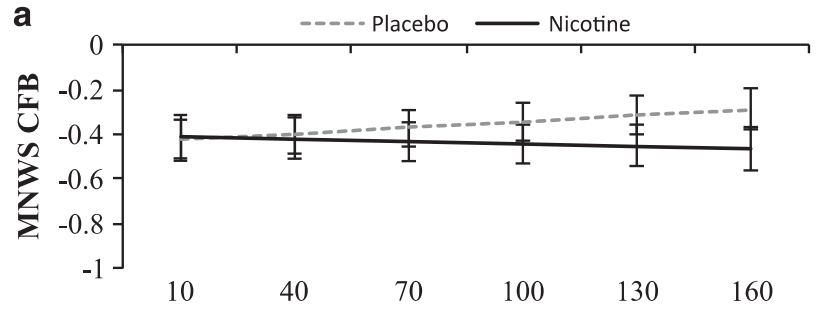

Time Post Patch (min)

C

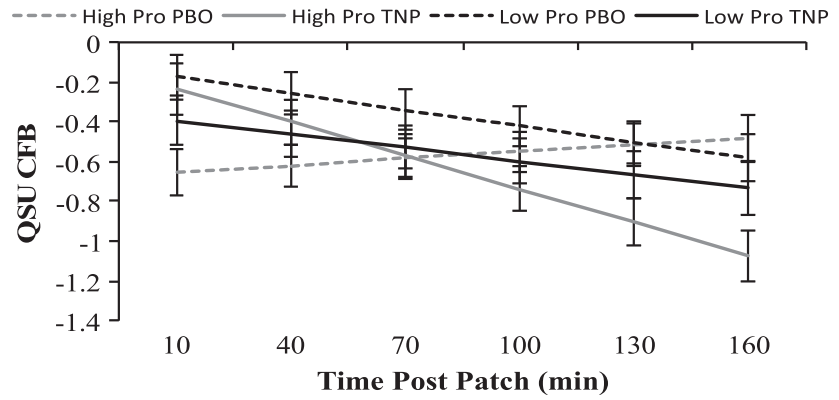

b

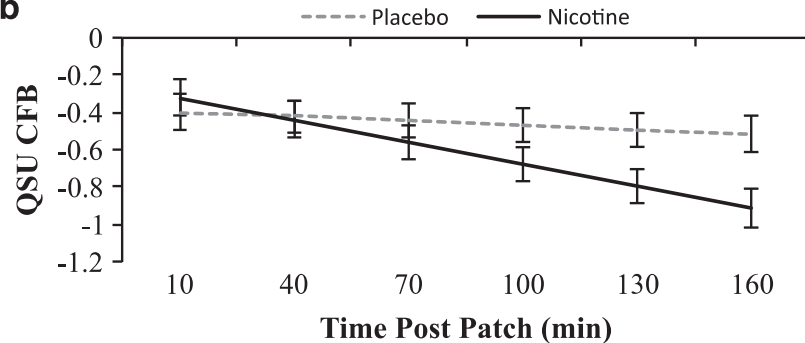

d

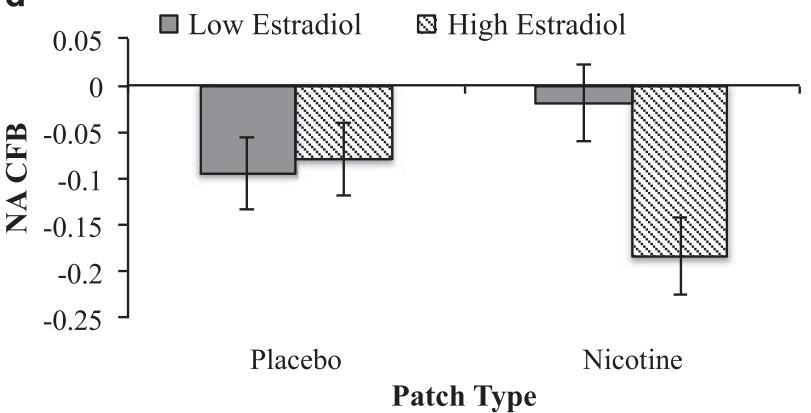

Figure I Interactions of patch-type, time, and ovarian hormones. Note. (a and b) Estimated marginal means \pm standard error over time for interaction effects between patch-type $\times$ time. (c) Estimated marginal means \pm standard error at low (I SD below mean) and high (I SD above mean) progesterone over time. (d) Estimated marginal means \pm standard error at low (I SD below mean) and high (I SD above mean) estradiol. CFB, change from baseline; QSU, questionnaire of smoking urges; NA, negative affect; Pro, progesterone; TNP, transdermal nicotine patch; PBO, transdermal placebo patch.

progesterone, estradiol, and $\mathrm{P} / \mathrm{E}$ ratio on smoking behavior depend on intention to quit smoking.

A key innovation of this research is our parsing of intraand inter-individual covariance in our statistical models. Intra-individual effects are akin to addressing what occurs following a natural spike or trough relative to one's mean level. The psychobiological impact of many neuropsychoactive compounds is dependent on previous exposure, such that the acceleration (or deceleration) of blood levels can have important effects, irrespective of the absolute level. Intra-individual variation in hormone levels may reflect a similar phenomenon and the data report in this study may reflect the effect of recent acceleration or deceleration of progesterone and estradiol on tobacco withdrawal, NA, urge, and smoking behavior. By contrast, between-person hormone variation may reflect a general propensity towards hormone levels that are higher relative to the general population, regardless of the respective phase of the menstrual cycle. Such variation could reflect the chronic effect of hormone exposure on smoking behavior, effects of smoking on hormone variation, or other individual difference factors that associate with phenotypic hormone variance (eg, menstrual cycle length, pubertal timing).

The results of this study need to be considered in the context of the study's limitations. First, this study was conducted in non-treatment-seeking daily smokers and may not generalize to treatment-seeking samples. Secondly, ovarian hormone levels were assessed a maximum of three times. Thus, we are unable to determine true between-subject mean ovarian hormone levels. More frequent assessments may provide information in regards to how hormonal profiles may differ between women and how these profiles may affect smoking-related outcomes. Another limitation is that this study only included an acute application of the patch (ie, $4 \mathrm{~h}$ ) with no pre-treatment. It is possible that the interactions between ovarian hormones and TNP may differ depending on whether nicotine levels are at a steady state. It is also possible that smoking a cigarette, which includes both pharmacological and sensorimotor effects, may interact with ovarian hormones differently than what was found in this study. Lastly, the analog smoking reinstatement task did not assess for smoking topography. Given previous studies showing that puff volume may differ depending on hormonal levels (Schiller et al, 2012), differences in smoking topography may have affected smoking behaviors (eg, differences in puff intensity between periods of high/low progesterone could influence the number of cigarettes one feels the need to smoke to relieve negative withdrawal symptoms during abstinence).

Despite these limitations, this study provides evidence that within-subject changes in estradiol and progesterone may interact with TNP to impact withdrawal- and smokingrelated outcomes. Phase-based studies investigating cessation outcomes have been mixed (Weinberger et al, 2015), but have been suggestive that TNP may moderate phase-based effects on cessation success (Franklin and Allen, 2009). The current results provide support that the effects of ovarian hormones on withdrawal- and smoking-related outcomes may vary depending on TNP. Additionally, phase-based studies can often overlook important hormonal shifts throughout the menstrual cycle. The results of this study suggest that within-person changes in hormonal levels may directly impact withdrawal- and smoking-related outcomes independent of menstrual cycle phase. Thus, these findings suggest that menstrual-cycle-based studies need to account for hormonal shifts that occur in commonly used phases (eg, estradiol levels moving from low to high in the follicular phase). 
Table 2 Effects of Progesterone on Smoking-Related Outcomes

\begin{tabular}{|c|c|c|c|c|c|c|c|c|c|c|c|c|c|}
\hline & \multicolumn{3}{|c|}{ MNWS } & \multicolumn{3}{|c|}{ QSU } & \multicolumn{3}{|c|}{ NA } & \multicolumn{2}{|c|}{ Length delayed } & \multicolumn{2}{|c|}{ Cigs smoked } \\
\hline & Model I & Model 2 & Model 3 & Model I & Model 2 & Model 3 & Model I & Model 2 & Model 3 & Model I & Model 2 & Model I & Model 2 \\
\hline \multicolumn{14}{|l|}{ Fixed effects } \\
\hline Intercept & -0.51 & -0.51 & -0.51 & -0.47 & -0.47 & -0.50 & -0.11 & -0.11 & -0.11 & 25.10 & 25.10 & 0.79 & 0.79 \\
\hline Patch & 0.08 & 0.08 & 0.09 & 0.06 & 0.06 & 0.10 & 0.00 & 0.01 & 0.01 & | 4.88 *** & | $4.88 * *$ & -0.47 & -0.47 \\
\hline Time & 0.03 & 0.03 & 0.03 & -0.02 & -0.03 & -0.02 & 0.00 & 0.00 & 0.00 & & & & \\
\hline Patch $\times$ Time & -0.04 & -0.04 & -0.04 & $-0.09 * * * *$ & $-0.09 * * * *$ & $-0.09 * * * *$ & 0.00 & 0.00 & 0.00 & & & & \\
\hline Progesterone -WS & -0.67 & -0.70 & -0.81 & -0.92 & -1.92 & -2.99 ****** & $-0.63 * * * *$ & -0.02 & -0.16 & -7.11 & -6.83 & 0.82 & 1.20 \\
\hline Progesterone-WS $\times$ Patch & & -0.34 & -0.02 & & 0.81 & $3.97 * * *$ & & -0.67 & -0.27 & & -0.65 & & -0.88 \\
\hline Progesterone-WS $\times$ Time & & 0.07 & 0.12 & & 0.27 & $0.72 * * *$ & & -0.14 & -0.08 & & & & \\
\hline Progesterone - WS $\times$ Patch $\times$ Time & & & -0.14 & & & -1.35 ***** & & & -0.17 & & & & \\
\hline
\end{tabular}

Abbreviation: WS, within-subject.

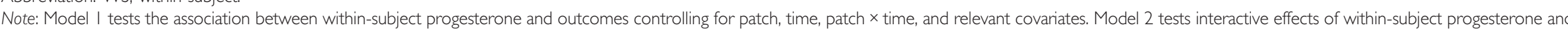

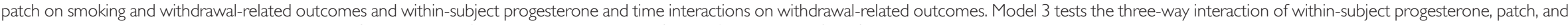

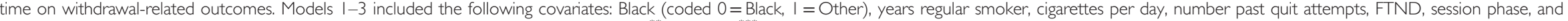

between-subject progesterone levels. Patch coded $0=0 \mathrm{mg}$ nicotine, $\mathrm{I}=2 \mathrm{I} \mathrm{mg}$ nicotine. ${ }^{* *} p<0.003,{ }^{* * *} p<0.00 \mathrm{I}$

Table 3 Effects of Estradiol on Smoking-Related Outcomes

\begin{tabular}{|c|c|c|c|c|c|c|c|c|c|c|c|c|c|}
\hline & \multicolumn{3}{|c|}{ MNWS } & \multicolumn{3}{|c|}{ QSU } & \multicolumn{3}{|c|}{ NA } & \multicolumn{2}{|c|}{ Length delayed } & \multicolumn{2}{|c|}{ Cigs smoked } \\
\hline & Model I & Model 2 & Model 3 & Model I & Model 2 & Model 3 & Model I & Model 2 & Model 3 & Model I & Model 2 & Model I & Model 2 \\
\hline \multicolumn{14}{|l|}{ Fixed effects } \\
\hline Intercept & -0.51 & -0.52 & -0.53 & -0.52 & -0.51 & -0.52 & -0.13 & -0.14 & -0.15 & $26.25 * *$ & $26.25 * * *$ & 0.77 & 0.77 \\
\hline Patch & 0.03 & 0.04 & 0.04 & 0.07 & 0.07 & 0.07 & -0.01 & -0.01 & -0.01 & 16.03***** & 16.16 ***** & -0.49 & -0.49 \\
\hline Time & 0.03 & 0.03 & 0.03 & -0.02 & -0.02 & -0.03 & 0.00 & 0.00 & 0.00 & & & & \\
\hline Patch $\times$ Time & -0.04 & -0.04 & -0.04 & -0.10 **** & $-0.09 * * *$ & $-0.09 * * * *$ & 0.00 & 0.00 & 0.00 & & & & \\
\hline Estradiol—WS & -0.01 & 0.05 & 0.00 & 0.00 & -0.05 & -0.10 & $-0.05 * *$ & 0.05 & 0.03 & 0.44 & -0.62 & 0.03 & 0.10 \\
\hline Estradiol-WS $\times$ Patch & & -0.15 & -0.04 & & 0.12 & 0.23 & & $-0.12 * * *$ & -0.09 & & 2.08 & & -0.15 \\
\hline Estradiol—WS $\times$ Time & & 0.00 & 0.02 & & -0.01 & 0.01 & & -0.01 & -0.01 & & & & \\
\hline Estradiol—WS $\times$ Patch $\times$ Time & & & -0.04 & & & -0.04 & & & -0.01 & & & & \\
\hline
\end{tabular}

Abbreviation: WS, within-subject.

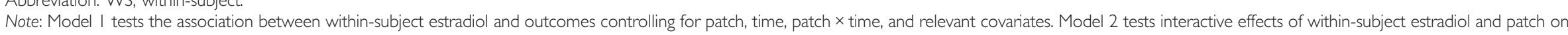
smoking and withdrawal-related outcomes and within-subject estradiol and time interactions on withdrawal-related outcomes. Model 3 tests the three-way interaction of within-subject estradiol, patch, and time on

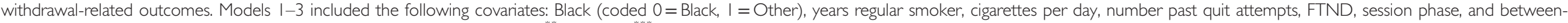
subject estradiol levels. Patch coded $0=0 \mathrm{mg}$ nicotine, I $=2 \mathrm{I} \mathrm{mg} \mathrm{nicotine.}{ }^{* *} p<0.003,{ }^{* * * *} p<0.00$ I. 


\section{FUNDING AND DISCLOSURE}

This research was supported by funds from Tobacco-Related Disease Research Program of the University of California, Grant Number 22FT-0062, NIDA grants K01-DA040043 and R21-DA034768. The funding agencies had no role in the design and conduct of the study; collection, management, analyses, and interpretation of the data; and preparation, review, or approval of the manuscript and the decision to submit it for publication. Preliminary analyses of this data have been presented at the 2017 Collaborative Perspectives on Addiction conference. Adam Leventhal received compensation for grant review for the NIH ARM study section. The remaining authors declare no conflict of interest.

\section{REFERENCES}

Albert K, Pruessner J, Newhouse P (2015). Estradiol levels modulate brain activity and negative responses to psychosocial stress across the menstrual cycle. Psychoneuroendocrinology 59: 14-24.

Choe JK, Khan-Dawood FS, Dawood MY (1983). Progesterone and estradiol in the saliva and plasma during the menstrual cycle. Am J Obstet Gynecol 147: 557-562.

Cox LS, Tiffany ST, Christen AG (2001). Evaluation of the brief questionnaire of smoking urges (QSU-brief) in laboratory and clinical settings. Nicotine Tob Res 3: 7-16.

DeVito EE, Herman AI, Waters AJ, Valentine GW, Sofuoglu M (2014). Subjective, physiological, and cognitive responses to intravenous nicotine: effects of sex and menstrual cycle phase. Neuropsychopharmacology 39: 1431-1440.

Enders CK, Tofighi D (2007). Centering predictor variables in cross-sectional multilevel models: a new look at an old issue. Psychol Methods 12: 121-138.

Engman J, Linnman C, Van Dijk KR, Milad MR (2016). Amygdala subnuclei resting-state functional connectivity sex and estrogen differences. Psychoneuroendocrinology 63: 34-42.

Fehring RJ, Schneider M, Raviele K (2006). Variability in the phases of the menstrual cycle. J Obstet Gynecol Neonatal Nurs 35: 376-384.

Franklin TR, Allen SS (2009). Influence of menstrual cycle phase on smoking cessation treatment outcome: a hypothesis regarding the discordant findings in the literature. Addiction 104: 1941-1942.

Gilbert DG, Izetelny A, Radtke R, Hammersley J, Rabinovich NE, Jameson TR et al (2005). Dopamine receptor (DRD2) genotypedependent effects of nicotine on attention and distraction during rapid visual information processing. Nicotine Tob Res 7: 361-379.

Goletiani NV, Siegel AJ, Lukas SE, Hudson JI (2015). The effects of smoked nicotine on measures of subjective States and hypothalamic-pituitary-adrenal axis hormones in women during the follicular and luteal phases of the menstrual cycle. J Addict Med 9: 195-203.

Heatherton TF, Kozlowski LT, Frecker RC, Fagerstrom KO (1991). The Fagerstrom Test for Nicotine Dependence: a revision of the Fagerstrom Tolerance Questionnaire. Br J Addict 86: 1119-1127.

Hedeker D, Mermelstein RJ, Demirtas H (2012). Modeling betweensubject and within-subject variances in ecological momentary assessment data using mixed-effects location scale models. Stat Med 31: 3328-3336.

Henningsson S, Madsen KH, Pinborg A, Heede M, Knudsen GM, Siebner HR et al (2015). Role of emotional processing in depressive responses to sex-hormone manipulation: a pharmacological fMRI study. Translational psychiatry 5: e688.

Hughes JR, Hatsukami D (1986). Signs and symptoms of tobacco withdrawal. Arch Gen Psychiatry 43: 289-294. 
Japuntich SJ, Leventhal AM, Piper ME, Bolt DM, Roberts LJ, Fiore MC et al (2011). Smoker characteristics and smoking-cessation milestones. Am J Prev Med 40: 286-294.

Leeman RF, O'Malley SS, White MA, McKee SA (2010). Nicotine and food deprivation decrease the ability to resist smoking. Psychopharmacology (Berl) 212: 25-32.

Leventhal AM, Waters AJ, Boyd S, Moolchan ET, Lerman C, Pickworth WB (2007). Gender differences in acute tobacco withdrawal: effects on subjective, cognitive, and physiological measures. Exp Clin Psychopharmacol 15: 21-36.

Leventhal AM, Waters AJ, Moolchan ET, Heishman SJ, Pickworth WB (2010). A quantitative analysis of subjective, cognitive, and physiological manifestations of the acute tobacco abstinence syndrome. Addict Behav 35: 1120-1130.

Lynch WJ, Roth ME, Carroll ME (2002). Biological basis of sex differences in drug abuse: preclinical and clinical studies. Psychopharmacology (Berl) 164: 121-137.

Lynch WJ, Sofuoglu M (2010). Role of progesterone in nicotine addiction: evidence from initiation to relapse. Exp Clin Psychopharmacol 18: 451-461.

McKee SA (2009). Developing human laboratory models of smoking lapse behavior for medication screening. Addict Biol 14: 99-107.

McKee SA, Krishnan-Sarin S, Shi J, Mase T, O'Malley SS (2006). Modeling the effect of alcohol on smoking lapse behavior. Psychopharmacology (Berl) 189: 201-210.

McKee SA, Smith PH, Kaufman M, Mazure CM, Weinberger AH (2015). Sex differences in varenicline efficacy for smoking cessation: a meta-analysis. Nicotine Tob Res 18: 1002-1011.

Milivojevic V, Sinha R, Morgan PT, Sofuoglu M, Fox HC (2014). Effects of endogenous and exogenous progesterone on emotional intelligence in cocaine-dependent men and women who also abuse alcohol. Hum Psychopharmacol 29: 589-598.

Mumford SL, Steiner AZ, Pollack AZ, Perkins NJ, Filiberto AC, Albert PS et al (2012). The utility of menstrual cycle length as an indicator of cumulative hormonal exposure. J Clin Endocrinol Metab 97: E1871-E1879.

Pang RD, Leventhal AM (2013). Sex differences in negative affect and lapse behavior during acute tobacco abstinence: a laboratory study. Exp Clin Psychopharmacol 21: 269-276.

Pang RD, Zvolensky MJ, Schmidt NB, Leventhal AM (2015). Gender differences in negative reinforcement smoking expectancies. Nicotine Tob Res 17: 750-754.

Payne TJ, Smith PO, McCracken LM, McSherry WC, Antony MM (1994). Assessing nicotine dependence: a comparison of the Fagerstrom Tolerance Questionnaire (FTQ) with the Fagerstrom Test for Nicotine Dependence (FTND) in a clinical sample. Addict Behav 19: 307-317.
Riad-Fahmy D, Read GF, Walker RF (1983). Salivary steroid assays for assessing variation in endocrine activity. J Steroid Biochem 19: 265-272.

Saladin ME, McClure EA, Baker NL, Carpenter MJ, Ramakrishnan V, Hartwell KJ et al (2015). Increasing progesterone levels are associated with smoking abstinence among free-cycling women smokers who receive brief pharmacotherapy. Nicotine Tob Res 17: 398-406.

Schiller CE, Saladin ME, Gray KM, Hartwell KJ, Carpenter MJ (2012). Association between ovarian hormones and smoking behavior in women. Exp Clin Psychopharmacol 20: 251-257.

Shirtcliff EA, Granger DA, Schwartz EB, Curran MJ, Booth A, Overman WH (2000). Assessing estradiol in biobehavioral studies using saliva and blood spots: simple radioimmunoassay protocols, reliability, and comparative validity. Horm Behav 38: 137-147.

Smith PH, Kasza KA, Hyland A, Fong GT, Borland R, Brady K et al (2015). Gender differences in medication use and cigarette smoking cessation: results from the International Tobacco Control Four Country Survey. Nicotine Tob Res 17: 463-472.

Sofuoglu M, Babb DA, Hatsukami DK (2001). Progesterone treatment during the early follicular phase of the menstrual cycle: effects on smoking behavior in women. Pharmacol Biochem Behav 69: 299-304.

Sofuoglu M, Mouratidis M, Mooney M (2011). Progesterone improves cognitive performance and attenuates smoking urges in abstinent smokers. Psychoneuroendocrinology 36: 123-132.

Toll BA, Schepis TS, O'Malley SS, McKee SA, Krishnan-Sarin S (2007). Subjective reactivity to the first cigarette of the day as a predictor of smoking relapse: a preliminary study. Drug Alcohol Depend 89: 302-305.

Watson D, Clark LA, Tellegen A (1988). Development and Validation of Brief Measures of Positive and Negative Affect: The PANAS Scales Vol 54. American Psychological Association: USA., pp 1063-1070.

Weinberger AH, Smith PH, Allen SS, Cosgrove KP, Saladin ME, Gray KM et al (2015). Systematic and meta-analytic review of research examining the impact of menstrual cycle phase and ovarian hormones on smoking and cessation. Nicotine Tob Res 17: 407-421.

Wetherill RR, Franklin TR, Allen SS (2016). Ovarian hormones, menstrual cycle phase, and smoking: a review with recommendations for future studies. Curr addict rep 3: 1-8.

Worthman CM, Stallings JF, Hofman LF (1990). Sensitive salivary estradiol assay for monitoring ovarian function. Clin Chem 36: 1769-1773.

Wu PC, Hsueh KC, Mar GY, Hsueh SC, Tu MS, McRobbie H et al (2015). Gender differences in outcome of an attempt to stop smoking among smokers attending a smoking cessation clinic in Taiwan: 3-year follow-up study. Eval Health Prof 39: 317-325.

Supplementary Information accompanies the paper on the Neuropsychopharmacology website (http://www.nature.com/npp) 